\title{
Increased expression of p38 mitogen- activated protein kinase is related to the acute renal lesions induced by gentamicin
}

\section{R.A. Volpini ${ }^{1}$, A.P.C. Balbi ${ }^{1}$, \\ R.S. Costa ${ }^{2}$ and \\ T.M. Coimbra ${ }^{1}$}

\author{
${ }^{1}$ Departamento de Fisiologia, ${ }^{2}$ Departamento de Patologia, \\ Faculdade de Medicina, Universidade de São Paulo, Ribeirão Preto, \\ SP, Brasil
}

\begin{abstract}
Correspondence

T.M. Coimbra

Departamento de Fisiologia

FMRP, USP

Av. Bandeirantes, 3900

14049-900 Ribeirão Preto, SP

Brasil

Fax: +55-16-3633-0017

E-mail: tmcoimbr@fmrp.usp.br

Research supported by FAPESP.

R.S. Costa and T.M. Coimbra are

recipients of CNPq fellowships.

.......................

Received July 26, 2005

Accepted February 22, 2006

........................

Mitogen-activated protein kinases (MAPK) may be involved in the pathogenesis of acute renal failure. This study investigated the expression of p-p38 MAPK and nuclear factor kappa B (NF- $\mathrm{kB})$ in the renal cortex of rats treated with gentamicin. Twenty rats were injected with gentamicin, $40 \mathrm{mg} / \mathrm{kg}$, im, twice a day for 9 days, 20 with gentamicin + pyrrolidine dithiocarbamate (PDTC, an NF- $\kappa \mathrm{B}$ inhibitor), 14 with $0.15 \mathrm{M} \mathrm{NaCl}, i m$, twice a day for 9 days, and 14 with $0.15 \mathrm{M} \mathrm{NaCl}$, im, twice a day for 9 days and PDTC, $50 \mathrm{mg} \mathrm{kg}^{-1} \mathrm{day}^{-1}$, ip, twice a day for 15 days. The animals were killed 5 and 30 days after the last of the injections and the kidneys were removed for histological, immunohistochemical and Western blot analysis and for nitrate determination. The results of the immunohistochemical study were evaluated by counting the p-p38 MAPK-positive cells per area of renal cortex measuring $0.05 \mathrm{~mm}^{2}$. Creatinine was measured by the Jaffé method in blood samples collected 5 and 30 days after the end of the treatments. Gentamicin-treated rats presented a transitory increase in plasma creatinine levels. In addition, animals killed 5 days after the end of gentamicin treatment presented acute tubular necrosis and increased nitrate levels in the renal cortex. Increased expression of p-p38 MAPK and NF- $\kappa \mathrm{B}$ was also observed in the kidneys from these animals. The animals killed 30 days after gentamicin treatment showed residual areas of interstitial fibrosis in the renal cortex, although the expression of p-p38 MAPK in their kidneys did not differ from control. Treatment with PDTC reduced the functional and structural changes induced by gentamicin as well as the expression of p-p38 MAPK and NF- $\kappa \mathrm{B}$. The increased expression of p-p38 MAPK and NF- $\mathrm{kB}$ observed in these rats suggests that these signaling molecules may be involved in the pathogenesis of tubulointerstitial nephritis induced by gentamicin.
\end{abstract}

Key words

- p38 mitogen-activated protein kinase

- Nuclear factor- $\mathrm{KB}$

- Inflammation

- Renal fibrosis

- Gentamicin-induced

acute tubular necrosis

- Nitric oxide
Cell growth, differentiation and apoptosis are regulated by a variety of extracellular signals. The type, duration and magnitude of these signals are efficiently transmitted to the inside of the cells, where signaling complexes are assembled for appropriate inte- gration and processing (1,2). Mitogen-activated protein kinases (MAPK) are important mediators involved in the intracellular network of interaction proteins that transduce extracellular stimuli to intracellular responses (3). Three distinct MAPK pathways have 
been described in mammalian cells: extracellular signal-regulated kinase, c-Jun-N-terminal kinase, and p38 MAPK (4).

p38 MAPK is a ubiquitous, highly conserved protein kinase that plays an important role in the inflammatory response and in the apoptosis process $(2,5)$. p38 MAPK is activated by cytokines and cellular stress, and its activation results in increased production of inflammatory cytokine genes including interleukin- $1 \beta$ and tumor necrosis factor- $\alpha$ (TNF- $\alpha)(5,6)$. There is also evidence that p38 MAPK may be involved in nuclear factor kappa B (NF- $\kappa \mathrm{B}$ ) activation (7). NF- $\kappa \mathrm{B}$ is an important transcription factor which is present in the cytoplasm of every cell type in an inactive form and, upon stimulation, is released from an inhibitory subunit (IKB) and translocates into the nucleus, promoting the transcriptional activation of target genes related to the inflammatory process such as interleukin- $1 \beta$ and TNF- $\alpha$ (8).

Gentamicin treatment provokes acute tubular necrosis and acute renal failure in about $20 \%$ of high-risk patients (9). Animal models of aminoglycoside nephrotoxicity also present residual areas of interstitial fibrosis in the renal cortex and progressive tubular injury $(10,11)$. Therefore, since there is evidence that both the MAPK and NF- $\mathrm{\kappa B}$ systems can be activated by oxidative stress in gentamicin-treated animals, we investigated the expression of p-p38 MAPK and NF- $\mathrm{KB}$ in the kidney during the evolution of tubulointerstitial nephritis and its relationship with histological features and renal function in gentamicin- or gentamicin + pyrrolidine dithiocarbamate (PDTC, an NF- $\mathrm{BB}$ inhibitor)-treated rats.

Sixty-eight female Wistar rats (180-200 g) were used. The animals were divided into four groups: group $1(\mathrm{~N}=20)$, rats injected with gentamicin (Schering-Plough S/A, Rio de Janeiro, RJ, Brazil), $40 \mathrm{mg} / \mathrm{kg}$, im, twice a day for 9 days; group $2(\mathrm{~N}=20)$ rats injected with gentamicin, $\mathrm{im}$, twice a day for 9 days and PDTC, $50 \mathrm{mg} \mathrm{kg}^{-1} \mathrm{day}^{-1}$, ip, twice a day for 15 days, starting one day before the first gentamicin injection; group $3(\mathrm{~N}=14)$, control, rats injected with $0.15 \mathrm{M} \mathrm{NaCl}$, im, twice a day for 9 days; group $4(\mathrm{~N}=14)$, control PDTC, rats injected with $0.15 \mathrm{M}$ $\mathrm{NaCl}, i m$, twice a day for 9 days and PDTC, $50 \mathrm{mg} \mathrm{kg}^{-1} \mathrm{day}^{-1}$, ip, twice a day for 15 days, starting 1 day before the first gentamicin injection.

Blood samples were collected 5 and 30 days after the end of treatment with gentamicin or $\mathrm{NaCl}$ to quantify creatinine (12). The animals were killed on the same days as blood collection, 32 rats at day 5: 8 injected with gentamicin, 10 with gentamicin + PDTC, 7 with $\mathrm{NaCl}$ and 7 with $\mathrm{NaCl}+$ PDTC and 36 rats at day 30: 12 injected with gentamicin, 10 with gentamicin + PDTC, 7 with $\mathrm{NaCl}$ and 7 with $\mathrm{NaCl}+$ PDTC. The organs were perfused with PBS $(0.15 \mathrm{M}$ $\mathrm{NaCl}$ containing $10 \mathrm{mM}$ sodium phosphate buffer, $\mathrm{pH}$ 7.4) and the kidneys were removed for histological and immunohistochemical analysis, for nitrate determination, and for Western blot studies.

Whole kidney cortical tissue from animals killed 5 days after the end of gentamicin or saline treatment was homogenized in $2 \mathrm{~mL}$ Triton X-100 lysis buffer ( $50 \mathrm{mM}$ Tris$\mathrm{HCl}, \mathrm{pH} 7.4,150 \mathrm{mM} \mathrm{NaCl}, 1 \%$ Triton X$100,1 \%$ deoxycholate, $0.1 \%$ SDS, $1 \mu \mathrm{g} / \mathrm{mL}$ aprotinin, $1 \mu \mathrm{g} / \mathrm{mL}$ leupeptin, and $1 \mathrm{mM}$ phenylmethylsulfonyl fluoride) at $4^{\circ} \mathrm{C}$. After incubation for $5 \mathrm{~min}$, the lysate was centrifuged at $4^{\circ} \mathrm{C}$ for $15 \mathrm{~min}$ at $10,000 \mathrm{~g}$ and stored frozen at $-70^{\circ} \mathrm{C}$. Lysate samples were thawed and deproteinized with $95 \%$ cold ethanol $\left(4^{\circ} \mathrm{C}\right)$ for $30 \mathrm{~min}$ and centrifuged. The supernatant solution was used for nitrate determination by the nitric oxide (NO)/ ozone chemiluminescence technique as described by Hampl et al. (13), using a Sievers Analyzer (Sievers 280 NOA, Sievers, Boulder, CO, USA).

The whole lysate was also used for Western blot studies. Thirty micrograms of protein was loaded per well and separated on a 
$10 \%$ SDS-PAGE gel. Gels were electroblotted onto a nitrocellulose membrane, incubated for $4 \mathrm{~h}$ in $30 \mathrm{~mL}$ blocking buffer (PBS, $5 \%$ skim milk), washed in buffer (PBS, $0.1 \%$ Tween 20, pH 7.6) and incubated with antip-p38 MAPK (Sigma-Aldrich, St. Louis, MO, USA; 1/800) or anti-NF-אB p65 (Santa Cruz Biotechnology, Santa Cruz, CA, USA; $1 / 200$ ) overnight at $4^{\circ} \mathrm{C}$. To determine the equivalence of protein loading the membranes were also incubated with anti- $\alpha_{1}-$ tubulin (Sigma; 1/2000) in 5\% bovine serum albumin overnight at $4^{\circ} \mathrm{C}$. Blots were washed and incubated with horseradish peroxidaseconjugated goat $1 / 10000$ anti-mouse or $1 / 5000$ anti-rabbit IgG (Dako, Glostrup, Denmark) for $1 \mathrm{~h}$ at room temperature. Membranes were washed and the membrane-bound antibody was detected using the Supersignal West Pico Chemiluminescent substrate (Pierce, Rockford, IL, USA) and captured on X-ray film. The intensity of the identified lanes was quantified by densitometry using Image J NIH image software and is reported in arbitrary units.

The kidneys from control animals and from animals killed 5 and 30 days after gentamicin or gentamicin + PDTC treatment were fixed in $4 \%$ paraformaldehyde, postfixed in Bouin's solution for 4-6 h, and processed for paraffin embedding. Four-micrometer histological sections were stained with Masson's trichrome and examined under the light microscope. In addition, the kidneys from control animals $(\mathrm{N}=7)$ and from animals killed 5 days or 30 days after gentamicin or gentamicin + PDTC treatment ( $\mathrm{N}=8$ per group) were subjected to immunohistochemical staining (14). The sections were incubated overnight at $4^{\circ} \mathrm{C}$ with $1 /$ 1,000 p-p38 MAPK monoclonal antibody and the reaction product was detected with an avidin-biotin-peroxidase complex (Vector Laboratories, Burlingame, CA, USA). The color reaction was developed with 3,3'diaminobenzidine (Sigma) and 8\% nickel chloride and the material was then counter- stained with methylgreen, dehydrated and mounted. To obtain the mean number of $\mathrm{p}$ p38MAPK-positive cells in the renal cortical tubulointerstitium, 30 grid fields measuring $0.05 \mathrm{~mm}^{2}$ each were evaluated, and mean counts per kidney were calculated. All data were submitted to analysis of variance with multiple comparisons by the Tukey test, with the level of significance set at $\mathrm{P}<0.05$.

Gentamicin-treated rats presented a transitory increase in plasma creatinine levels evaluated on day 5 after treatment $(1.65 \pm$ $0.34 \mathrm{mg} / \mathrm{dL})$ compared to control $(0.48 \pm$ $0.03 \mathrm{mg} / \mathrm{dL} ; \mathrm{P}<001$ ) that returned to normal levels at day $30(0.57 \pm 0.04 \mathrm{mg} / \mathrm{dL})$. This change observed on day 5 was less intense in gentamicin + PDTC-treated rats $(1.08 \pm 08$ $\mathrm{mg} / \mathrm{dL} ; \mathrm{P}<0.05)$. The histological study showed alterations characteristic of acute tubular necrosis in the renal cortex from the rats treated with gentamicin only and killed 5 days after treatment: tubular cell necrosis, focal areas of denuded basement membrane, intraluminal casts, swelling and flattening of proximal tubular cells with brush border loss, diffuse interstitial edema, and interstitial inflammatory cell infiltrates (Figure 1D,F). Histological features of chronic nephropathy such as interstitial fibrosis, tubular atrophy or dilatation were observed on day 30 after this treatment (data not shown). Glomerular morphology remained unchanged. We observed in previous studies that the percentage of damaged areas in the renal cortical tubulointerstitium from rats killed on day 30 after gentamicin treatment was $23.2 \%$ and the percentage of glomeruli with sclerosis was $6.4 \%$ despite the recovery of renal function. Thus, we can infer that those animals probably had enough normal glomeruli and tubulointerstitial areas to maintain renal function (15). Houghton et al. (10) also observed that glomerular filtration rate was preserved in rats with chronic gentamicin nephrotoxicity despite the progressive tubular injury. Treatment with PDTC attenuates the increase in plasma creatinine 

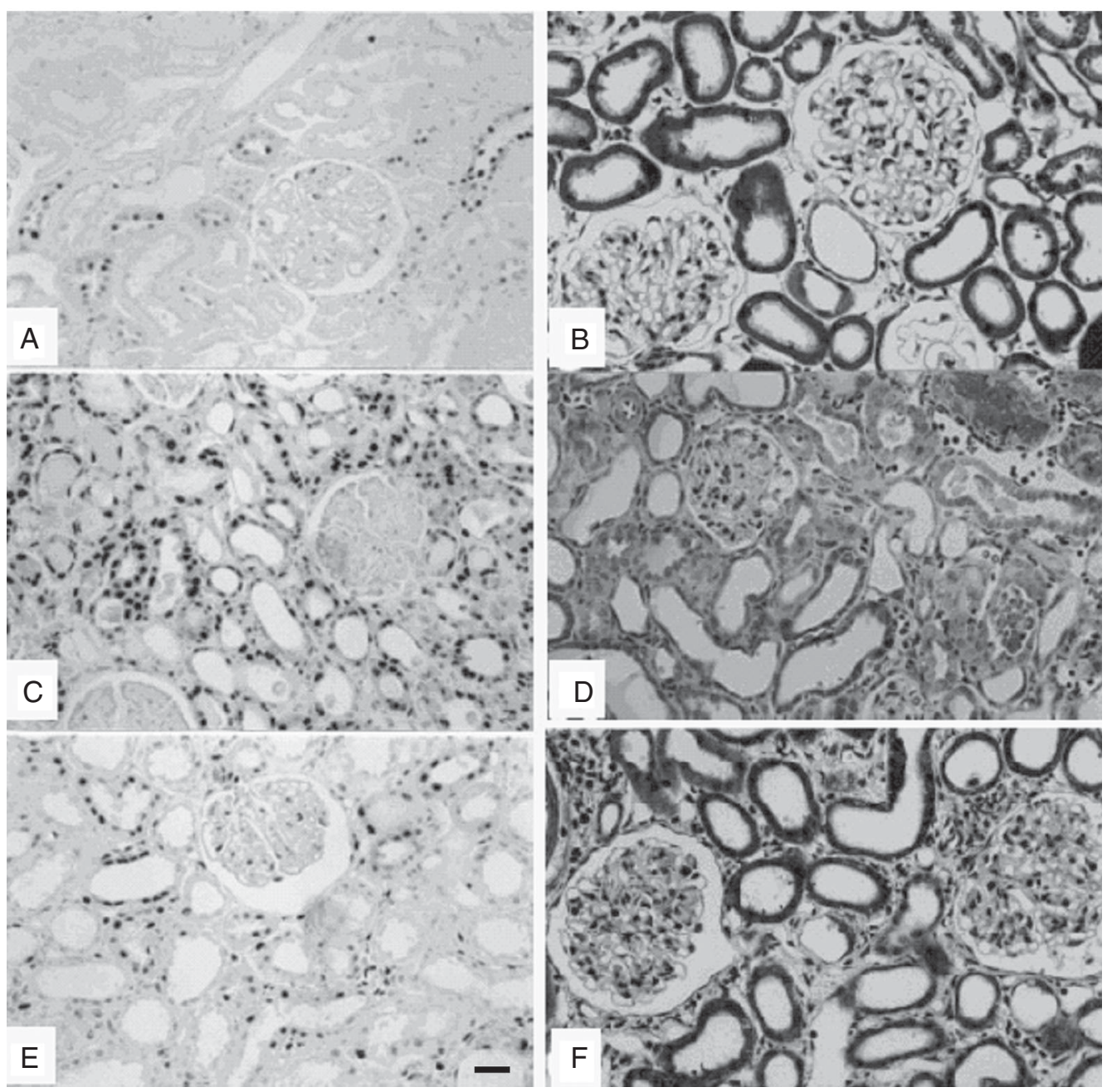

G

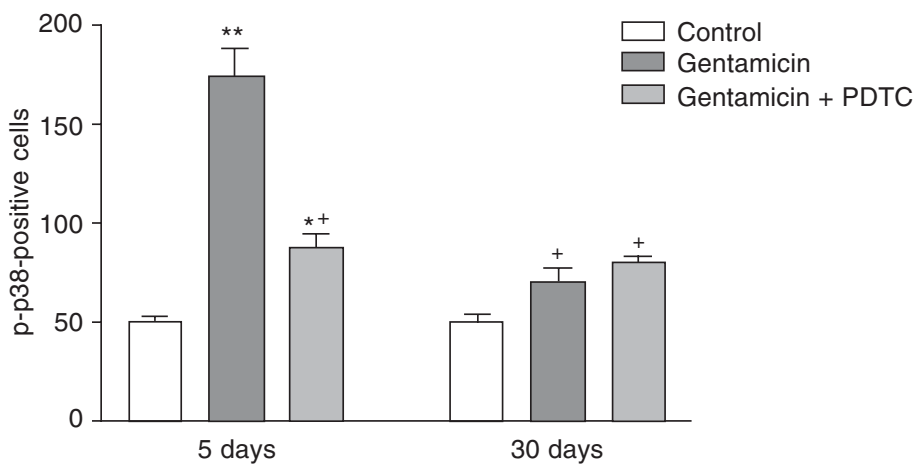

Figure 1. Immunolocalization of p-p38 MAPK in the renal cortex (A, C and E) and in Masson's trichrome-stained histological sections (B, D and F) from rats killed 5 days after treatment with $\mathrm{NaCl}(A$ and $B)$, gentamicin $(C$ and $D)$ or gentamicin + PDTC (E and F). Note that the number of p-p38 MAPK-positive cells is higher in $C$ than in $A$ and $E$ and that the acute tubular necrosis, flattening of proximal cells and increase in interstitial area are more intense in $D$ than in $F$. G, Number of p-p38-positive cells per grid field of renal cortex measuring $0.05 \mathrm{~mm}^{2}$. MAPK = mitogenactivated protein kinases; PDTC $=$ pyrrolidine dithiocarbamate. Original magnification X280 (G). Bar $=24.94 \mu \mathrm{m}$ for all panels. ${ }^{*} \mathrm{P}<0.05$ vs control; ${ }^{* *} \mathrm{P}<0.001$ vs control; ${ }^{+} \mathrm{P}<0.001$ vs gentamicin 5 days (Tukey test). 
levels and the histological changes observed in gentamicin-injected animals. PDTC administered alone did not affect the parameters of renal function and structure investigated (data not shown).

Our studies regarding the levels of tissue nitrate, a final product of NO reaction, showed that rats killed 5 days after gentamicin treatment presented significantly $(\mathrm{P}<$ $0.05)$ increased renal nitrate levels $(0.660 \pm$ $0.220 \mu \mathrm{M} / \mathrm{mg}$ protein) when compared to control animals $(0.032 \pm 0.006 \mu \mathrm{M} / \mathrm{mg}$ protein). Numerous effects of reactive oxygen species (ROS) in the regulation of cellular functions are mediated by $\mathrm{NO}$ (16). Although endothelial NO may have a beneficial role as a vasodilator by inducing an increase in renal blood flow and in glomerular filtration in these animals, excessive NO production can lead to cytotoxic injury. Peroxynitrite anion formation, protein tyrosine nitration, and hydroxyl radical production may contribute to the evolution of the renal lesions induced by gentamicin (17).

The immunohistochemical studies showed a significantly increased number of p-p38 MAPK-positive cells $(\mathrm{P}<0.001)$ in the renal cortex from gentamicin-treated animals killed 5 days after treatment (174.0 \pm 14.63 per $0.05 \mathrm{~mm}^{2}$ ) when compared to control $\left(50.0 \pm 2.65\right.$ per $\left.0.05 \mathrm{~mm}^{2}\right)$. Most cells from the proximal tubules of animals treated only with gentamicin expressed $\mathrm{p}$ p38. This alteration was reduced by treatment with PDTC and was not observed in the animals killed 30 days after gentamicin treatment. These data show that p38 MAPK is more activated in the tubulointerstitial cells during the early stages of this disease when the inflammatory process is more intense and diffuse. The p-p38 MAPK immunoreaction was localized in the tubular and interstitial cells, showing a diffuse distribution pattern in the renal cortex from gentamicin-treated animals killed 5 days after treatment (Figure 1C) and a focal distribution primarily in the damaged areas on day
30 (data not shown).

Western blot analysis performed with antibodies against p-p38 MAPK or NF- $\kappa B$ demonstrated the presence of $43-\mathrm{kDa}$ (pp38 MAPK) and 65-kDa (NF- $\mathrm{kB})$ protein lanes in the renal cortex from all groups studied. The corresponding lanes from gentamicin-treated animals killed 5 days after treatment were more prominent than those obtained for control and PDTC + gentamicin-treated animals (Figure 2). There was no
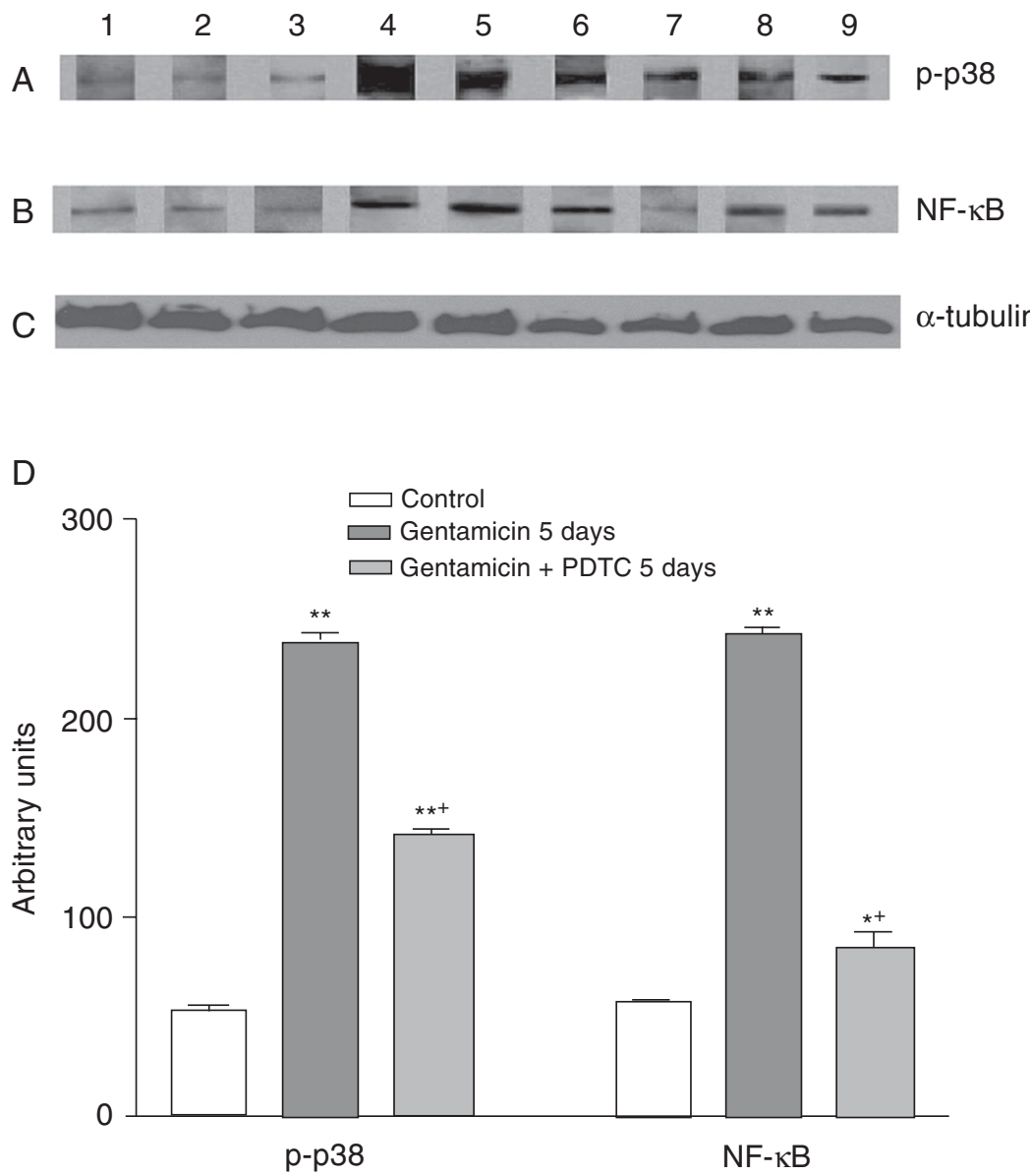

Figure 2. Western blot analysis of p38 MAPK (A), NF- $\mathrm{MB}(\mathrm{B})$ and $\alpha_{1}$-tubulin (C) in renal cortex from control rats (lanes 1-3), from rats killed 5 days after treatment with gentamicin (lanes 4-6), or gentamicin + PDTC (lanes 7-9). Note that the corresponding lanes from gentamicin-treated rats (4-6) are more prominent than those corresponding to the control or PDTC + gentamicin groups and that there was no difference in the intensity of the signal between the different groups for $\alpha_{1}$-tubulin $(C)$. $D$, Densitometry of $p$-p38 MAPK and NF- $\mathrm{B}$ lanes in the renal cortex from control rats $(\mathrm{N}=3)$ and from rats killed 5 days after treatment with gentamicin $(\mathrm{N}=3)$ or PDTC + gentamicin $(\mathrm{N}=3)$. Data are reported as mean \pm SEM. MAPK = mitogen-activated protein kinases; NF- $\mathrm{kB}=$ nuclear factor kappa $\mathrm{B}$; $\mathrm{PDTC}=$ pyrrolidine dithiocarbamate. ${ }^{*} \mathrm{P}<0.01$ vs control; ${ }^{*} \mathrm{P}<0.001$ vs control; ${ }^{+} \mathrm{P}<0.001$ vs gentamicin 5 days (Tukey test). 
difference in the intensity of the lanes for $\alpha_{1}$ tubulin between the different groups, showing the equivalence of protein loading (Figure $2 \mathrm{C}$ ). Several studies have shown that both the MAPK and NF- $\mathrm{KB}$ systems can be activated by oxidative stress (18), with consequent changes in gene expression that can progress to cell survival or cell death (19). PDTC as an antioxidant can reduce the ROS present in the gentamicin-induced inflammatory process $(18,20)$. PDTC also has a direct effect on NF- $\mathrm{KB}$ activation by blocking IKB degradation (20). It has been reported that specific and selective p38 MAPK inhibitors can block the production of inflammatory molecules, reducing the apoptotic cell death and ameliorating the acute renal injury observed in some animal models of renal disease such as anti-GBM glomerulonephritis and ischemia/reperfusion $(2,4)$. Furthermore, there is evidence that the production of TNF post-renal injury is triggered by the locally produced ROS, which activate NF- $\kappa B$ through $\mathrm{p} 38$ MAPK (7). The signaling cascade leading to inflammatory cytokine production includes the phospho- rylation of Ras, which in turn initiates the protein kinase cascade which ultimately leads to activation of the MAPK family of protein kinases. Activation of p38 MAPK can also induce NF- $\kappa B$ activation and subsequent transcription of inflammatory cytokines (7). In addition, these inflammatory cytokines and ROS can act as a positive feedback loop, amplifying the inflammatory process observed in acute tubular necrosis.

Our data show that p-p38 MAPK expression is increased during the development of gentamicin-induced interstitial nephritis and that such alteration is associated with enhancement of NF-KB expression and of the inflammatory process in the renal cortex, suggesting that the $\mathrm{p} 38$ MAPK pathway may be involved in the renal lesions induced by gentamicin.

\section{Acknowledgments}

The authors thank Cleonice G.A. da Silva, Erika Delloiagono, Adriana L.G. de Almeida, and Rubens Fernando de Melo for expert technical assistance.

\section{References}

1. di Mari JF, Davis R, Safirstein RL. MAPK activation determines renal epithelial cell survival during oxidative injury. Am J Physiol 1999; 277: F195-F203.

2. Stambe C, Atkins RC, Tesch GH, Kapoun AM, Hill PA, Schreiner $\mathrm{GF}$, et al. Blockade of p38 alpha MAPK ameliorates acute inflammatory renal injury in rat anti-GBM glomerulonephritis. J Am Soc Nephrol 2003; 14: 338-351.

3. Bokemeyer D, Ostendorf T, Kunter U, Lindemann M, Kramer HJ, Floege J. Differential activation of mitogen-activated protein kinases in experimental mesangioproliferative glomerulonephritis. J Am Soc Nephrol 2000; 11: 232-240.

4. Kumar S, Boehm J, Lee JC. p38 MAP kinases: key signalling molecules as therapeutic targets for inflammatory diseases. Nat Rev Drug Discov 2003; 2: 717-726.

5. Ohashi R, Nakagawa T, Watanabe S, Kanellis J, Almirez RG, Schreiner GF, et al. Inhibition of p38 mitogen-activated protein kinase augments progression of remnant kidney model by activating the ERK pathway. Am J Pathol 2004; 164: 477-485.

6. Bokemeyer D, Sorokin A, Dunn MJ. Multiple intracellular MAP kinase signaling cascades. Kidney Int 1996; 49: 1187-1198.
7. Donnahoo KK, Shames BD, Harken AH, Meldrum DR. Review article: the role of tumor necrosis factor in renal ischemia-reperfusion injury. J Urol 1999; 162: 196-203.

8. Guijarro C, Egido J. Transcription factor-kappa B (NF-kappa B) and renal disease. Kidney Int 2001; 59: 415-424.

9. Cronin RE, Henrich WL. Toxic nephropathies. In: Brenner BM (Editor), Brenner and Rector's The Kidney. Philadelphia: Saunders Company; 2000. p 1563-1596.

10. Houghton DC, Lee D, Gilbert DN, Bennett WM. Chronic gentamicin nephrotoxicity. Continued tubular injury with preserved glomerular filtration function. Am J Pathol 1986; 123: 183-194.

11. Houghton DC, English J, Bennett WM. Chronic tubulointerstitial nephritis and renal insufficiency associated with long-term "subtherapeutic" gentamicin. J Lab Clin Med 1988; 112: 694-703.

12. Fuhr J, Kaczmarczyk J, Kruttgen CD. A simple colorimetric method of inulin determination in renal clearance studies on metabolically normal subjects and diabetics. Klin Wochenschr 1955; 33: 729-730.

13. Hampl V, Walters CL, Archer SL. Determination of nitric oxide by the chemiluminescence reaction with ozone. In: Feelish M, Stamler JS (Editors), Methods in Nitric Oxide Research. New York: Wiley; 1996. 
14. Coimbra TM, Janssen U, Grone HJ, Ostendorf T, Kunter U, Schmidt $\mathrm{H}$, et al. Early events leading to renal injury in obese Zucker (fatty) rats with type II diabetes. Kidney Int 2000; 57: 167-182.

15. Geleilete TJ, Melo GC, Costa RS, Volpini RA, Soares TJ, Coimbra TM. Role of myofibroblasts, macrophages, transforming growth factor-beta endothelin, angiotensin-II, and fibronectin in the progression of tubulointerstitial nephritis induced by gentamicin. J Nephrol 2002; 15: 633-642.

16. Rodrigo R, Rivera G. Renal damage mediated by oxidative stress: a hypothesis of protective effects of red wine. Free Radic Biol Med 2002; 33: 409-422.
17. Klahr S. The role of L-arginine in hypertension and nephrotoxicity. Curr Opin Nephrol Hypertens 1998; 7: 547-550.

18. Martindale JL, Holbrook NJ. Cellular response to oxidative stress: signaling for suicide and survival. J Cell Physiol 2002; 192: 1-15.

19. Koul HK. Role of p38 MAP kinase signal transduction in apoptosis and survival of renal epithelial cells. Ann N Y Acad Sci 2003; 1010: 62-65.

20. Shen WH, Zhang CY, Zhang GY. Antioxidants attenuate reperfusion injury after global brain ischemia through inhibiting nuclear factorkappa B activity in rats. Acta Pharmacol Sin 2003; 24: 1125-1130. 